\title{
Electrooxidation of carbo/thiocarbohydrazide and their hydrazone derivatives at a glassy carbon electrode
}

\author{
G P MAMATHA, B S SHERIGARA* and K M MAHADEVAN \\ Department of Post-Graduate Studies in Industrial Chemistry, Kuvempu University, \\ Jnana Sahyadri, Shankaraghatta 577451 \\ e-mail: bssherigara $@$ rediffmail.com
}

MS received 13 September 2006; revised 9 May 2007

\begin{abstract}
Electrochemical oxidation of thio/carbohydrazide and their hydrazone derivatives Benzaldehyde thiocarbohydrazone [BTCH] diacetylene thiocarbohydrazone [DATCH] have been studied in Britton Robinson buffer in aqueous and nonaqueous media at a glassy carbon electrode. The effects of $\mathrm{pH}$, sweep rate, concentration, temperature and surfactants have been studied. The complex bis (carbo/ thiocabohydrazide) $\mathrm{Zn}$ (II) chloride was also subjected to voltammetric analysis in order to understand the reactivity both in free and metal bound states. The reaction conditions were optimized for the determination of above compounds in micrograms quantities by differential pulse voltammetry, analytical utility of this investigation is also highlighted.
\end{abstract}

Keywords. Voltammetry; carbo/thiocarbohydrazide; glassy carbon electrode; electrooxidation.

\section{Introduction}

Thiocarbohydrazide[TCH] and Carbohydrazide $[\mathrm{CH}]$ are important analytical reagents of tremendous utility. For example, TCH posses anticarcinogenic and antibacterial properties. ${ }^{1}$ It exhibits toxicity towards house-fly comparable to that of DDT. ${ }^{2}$ The fungicidal properties ${ }^{3}$ of thiocarbohydrazide have also been tested against different species. Thiocarbohydrazide is also used as an additive to prevent the excessive loss of cellulose during the alkaline work-up of wood pulp. $^{4}$

Carbohydrazide acts as a denaturing agent both for bovine serum albumin ${ }^{5}$ and for DNA. ${ }^{6}$ The effect is attributed to stabilisation of the denatured DNA relative to native DNA by decrease in the ion solvation power and an increase in the hydrophobic character of the solvent. Carbohydrazide in the form of its cobalt complex produces hypertension without toxicity along with a simultaneous acute pyridoxine deficiency in dogs. ${ }^{7}$ It also acts as a curing agent for epoxide-type resins. ${ }^{8}$ Finally polymeric carbohydrazide prepared from phenylcarbamic acid esters are used as pharmaceuticals. ${ }^{9}$

The potentiometric and kinetic studies of these compounds were carried out a decade ago. ${ }^{10-12}$ As a

\footnotetext{
*For correspondence
}

part of our continuing effort to understand the mechanism of electroreduction/oxidation of these molecules $^{13-17}$ we report here some recent results of electrochemical oxidation of $\mathrm{TCH}$ and $\mathrm{CH}$ and their hydrazone derivatives in aqueous solvents like DMF and DMSO at different $\mathrm{pH}$ on a glassy carbon electrode.

\section{Experimental}

\subsection{Reagents and chemicals}

All the above mentioned compounds were prepared in the laboratory in pure form by using standard procedures. ${ }^{18,19}$ Purities were checked by TLC, MP and spectral studies.

Thicocarbohydrazide was prepared by adding $\mathrm{CS}_{2}$ to a warm solution of hydrazine hydrate and water refluxing for $1 \mathrm{~h}^{18}$

Monothiocarbohydrazone derivative such as $\mathrm{BTCH}$, $\mathrm{Cl}-\mathrm{BTCH}, \mathrm{CH}_{3}-\mathrm{BTCH}$ were prepared by refluxing equimolar mixture of respective aldehyde and $\mathrm{TCH}$ with ethanol as solvent Diacetylidene thiocarbohydrazone was prepared by ${ }^{18}$ adding $50 \%$ excess of acetaldehyde in ethanol to a solution of thiocarbohydrazide in $1 \mathrm{~mol} / \mathrm{dm}^{3}$ acetic acid $(2: 1)$ and refluxing the resulting mixture for $1 \mathrm{~h}$. 
The complex bis(thiocarbohydrazide) zinc(II) chloride was prepared ${ }^{18}$ by mixing a warm solution of zinc chloride in dimethyl formamide water $(5: 1 \mathrm{v} / \mathrm{v})$ and thiocarbohydrazide in dimethyl formamide, in an approximately $1: 2$ mole ratio.

Carbohydrazide was prepared by mixing diethyl carbonate and $85 \%$ hydrazine hydrate in $1: 2.2$ molar ratio $^{19}$ refluxing the reaction mixture for about $6 \mathrm{~h}$.

The solvent used for the electrochemical study was water-DMSO $(60: 40)$ medium. All other reagents were of analytical grade. The solution was bubbled with nitrogen gas (99.99\%) before electrochemical studies.

\subsection{Instrumentation}

The electrochemical experiments were carried out using a potentiostat coupled with a data acquisition PC interface card fabricated at the Analytical Chemistry Division, Bhabha Atomic Research Centre, Trombay, compatible with an IBM personnel computer an linked to a printer. The electrochemical cell consisted of a glass container with a cap having holes for introducing electrodes and nitrogen. The cell was then maintained oxygen free by passing nitrogen over the solution. The reference electrode used was saturated calomel electrode (SCE). The auxillary and working electrodes were platinum foil and glassy carbon respectively, that were placed directly into the solution. Since the limiting (or peak) current in any type of voltammetry is temperature dependent, the cell was thermostated for the required temperature (295 K).

In a typical cyclic voltammetric experiment, the reaction mixture consisted of solution of substrate $\mathrm{TCH} / \mathrm{CH}$ solution in DMSO, water and Britton Robinson buffer as supporting electrolyte. A stream of nitrogen was passed over them after keeping the reaction mixture in a thermostat. The three electrodes were connected to a computer controlled potentiostat and required potential scan rate, current sensitivity, initial potential and final potential were given and the resulting current was measured as a function of the applied potential.

\subsection{Pretreatment of glassy carbon electrode}

Before each measurement, the glassy carbon surface was polished with a fine emery sheet and then rinsed with purified water. The supporting electrolyte was placed in the cell and several potential sweeps were applied to obtain a low background. Effective area of GCE was $0.069 \mathrm{~cm}^{2}$. The TCH/CH was added and the first potential sweep was registered.

\section{Results and discussion}

Cyclicvoltammetric oxidation of TCH (A) and $\mathrm{CH}$ (B) in DMSO : water medium was studied on a glassy carbon electrode surface using Britton Robinson buffer as a supporting electrolyte. The cyclic voltammogram showed a single irreversible anodic peak due to the oxidation of $-\mathrm{NH}_{2}$ moiety presumably involving four electrons (figure 1).

\subsection{Effect of $p H$}

Effect of $\mathrm{pH}$ on the peak potential and peak current was studied using $2 \mathrm{mM} \mathrm{TCH}$ and $\mathrm{CH}$ respectively in Britton-Robinson buffer from $\mathrm{pH} 4.6$ to 11.25. The anodic peak potential $E_{\mathrm{pa}}$ decreases from $916 \mathrm{mV}$ to $513 \mathrm{mV}$ for TCH and from $1103 \mathrm{mV}$ to $613 \mathrm{mV}$ for $\mathrm{CH}$ respectively, suggesting that the oxidation becomes easier at higher $\mathrm{pH}$ for both these. More interestingly, above $\mathrm{pH} 6.5$ the cyclic voltammogram showed two peaks indicating that oxidation take place in two steps involving three and one electrons. Peak width reflect this (figure 2).

\subsection{Effect of concentration}

The effect of concentration of $\mathrm{TCH}$ and $\mathrm{CH}$ were studied in DMSO-water media using a BrittonRobinson buffer as supporting electrolyte. As the concentration of $\mathrm{TCH}$ and $\mathrm{CH}$ were varied from

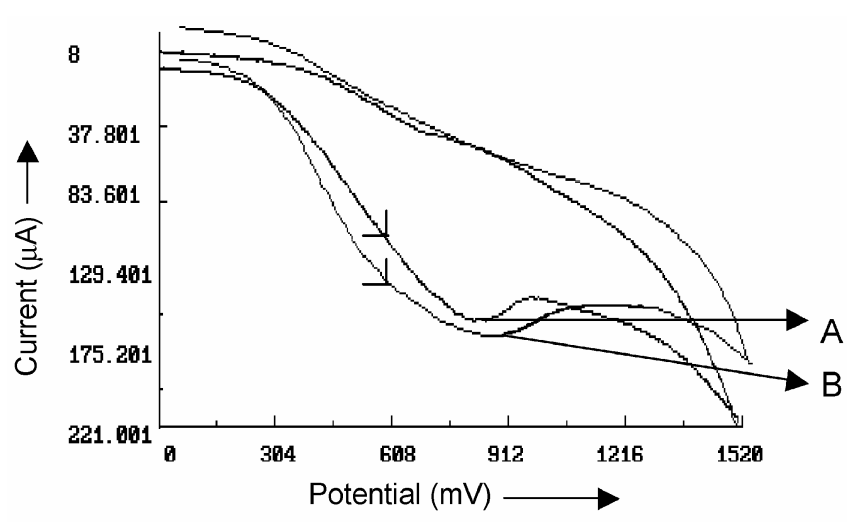

Figure 1. Cyclic voltammogram of $\mathrm{TCH}(\mathrm{A})$ and $\mathrm{CH}$ (B) at $\mathrm{pH}=5.0$ in Britton-Robinson buffer, scan rate $=$ $50 \mathrm{mVs}^{-1}$, medium $=$ DMSO $:$ water $(60: 40)$ at GCE. 
Table 1. Effect of concentration of TCH and $\mathrm{CH}$ on cyclic voltammetric parameters for the oxidation at GCE (electrode system : GCE/Pt/SCE medium = water : $\mathrm{DMSO}(60: 40 \mathrm{v} / \mathrm{v})$ Britton-Robinson buffer of $\mathrm{pH}=7.50)$

\begin{tabular}{|c|c|c|c|c|c|c|c|c|}
\hline \multirow{2}{*}{$\begin{array}{l}\text { Conc. of TCH } \\
\text { and } \mathrm{CH}(\mathrm{mM})\end{array}$} & \multicolumn{2}{|c|}{$E_{p a}(\mathrm{mV})$} & \multicolumn{2}{|c|}{$i_{p a}(\mu \mathrm{A})$} & \multicolumn{2}{|c|}{$\begin{array}{c}\text { Diffusion coefficient } \\
\left(D_{0} \times 10^{-5} \mathrm{~cm}^{2} \mathrm{~s}^{-1}\right)\end{array}$} & \multicolumn{2}{|c|}{$\begin{array}{c}\text { Standard heterogeneous } \\
\text { rate constant } \\
\left(k_{0} \times 10^{-5} \mathrm{~cm} \mathrm{~s}^{-1}\right)\end{array}$} \\
\hline & $\mathrm{TCH}$ & $\mathrm{CH}$ & TCH & $\mathrm{CH}$ & $\mathrm{TCH}$ & $\mathrm{CH}$ & $\mathrm{TCH}$ & $\mathrm{CH}$ \\
\hline 0.5 & 498 & 731 & 51.90 & 34.50 & 27.02 & $20 \cdot 73$ & 1.71 & $1 \cdot 14$ \\
\hline 1.0 & 506 & 841 & 88.20 & $62 \cdot 20$ & 23.41 & $20 \cdot 66$ & 1.45 & 1.02 \\
\hline 1.5 & 603 & 862 & $121 \cdot 20$ & 78.70 & 21.78 & $19 \cdot 32$ & 1.33 & 0.87 \\
\hline 2.0 & 690 & 1017 & 153.90 & 104.80 & 18.68 & $14 \cdot 11$ & 1.27 & $0 \cdot 86$ \\
\hline 2.5 & 707 & 1042 & $170 \cdot 70$ & $125 \cdot 20$ & $16 \cdot 44$ & 13.85 & 1.29 & 0.74 \\
\hline
\end{tabular}

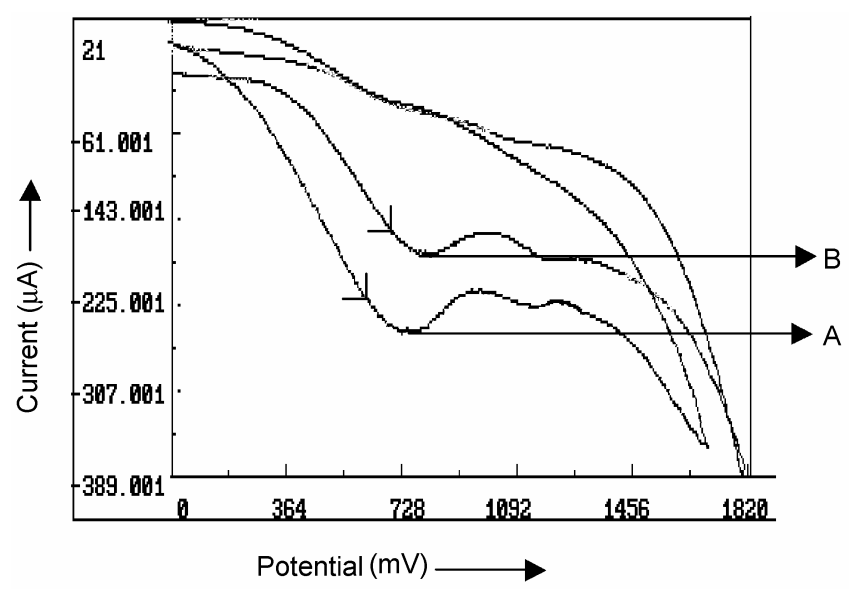

Figure 2. Cyclic voltammogram of $\mathrm{TCH}(\mathrm{A})$ and $\mathrm{CH}$ (B) at $\mathrm{pH}=6.5$ in Britton-Robinson buffer, scan rate $=$ $50 \mathrm{mVs}^{-1}$, medium $=$ DMSO : water $(60: 40)$ at GCE.

$0.5 \mathrm{mM}$ to $2.5 \mathrm{mM}$, the anodic current $i_{p a}$ values obtained were found to increase linearly with increase in concentration (table 1). The plot of $i_{p a}$ verses concentration of $\mathrm{TCH}$ and $\mathrm{CH}$ show linearity further indicating electrode process was diffusion controlled. ${ }^{20,21}$ It was also observed that the peak potential $E_{p a}$ and half peak potential $E_{p a / 2}$ were shifted towards more positive potential value with increase in concentration.

\subsection{Effect of scan rate}

The concentration of TCH and $\mathrm{CH}$ was kept constant at $2 \mathrm{~mm}$ in DMSO-water medium. The sweep rate was varied from 5 to $200 \mathrm{mVs}^{-1}$. The $i_{p a}$ was found to increase linearly with the square root of the scan rate $\left(v^{1 / 2}\right)$. These observations suggests that the process was diffusion controlled. ${ }^{22}$ The peak poten- tial was shifted towards the more positive values with an increase in the scan rate indicating that electrochemical process was irreversible. The cathodic charge transfer coefficients $(n)$ were evaluated by measuring the $E_{p}-E_{p / 2}$ using the expression. ${ }^{22}$

$$
E_{p}-E_{p / 2}=47.7 \mathrm{mV} / \alpha \mathrm{n},
$$

where $n$ is the number of electrons. The values found were $\alpha n=0.50 \pm 0.05$.

\subsection{Effect of solvent composition}

The effect of solvent composition on the electrooxidation of TCH and $\mathrm{CH}$ were studied from $20 \% \mathrm{v} / \mathrm{v}$ to $70 \% \mathrm{v} / \mathrm{v}$ DMSO and water in Britton-Robinson buffer. It was observed that as the percentage of solvent increase, the oxidation potential value shifted towards more positive value (table 2). The shift may be due to the inhibition of the electrode process by the solvent molecules adsorbed on the electrode ${ }^{23}$ and also due to dielectric effect.

\subsection{Effect of substituent}

In the presence of electron withdrawing and donating groups, oxidation occur at higher and lower potentials respectively. Accordingly benzaldehyde thiocarbohydrazone, $o$-chlorobenzaldehyde thiocarbohydrazone and methoxy benzaldehyde thiocarbohydrazone get oxidized at 849,893 and $829 \mathrm{mV}$ respectively.

\subsection{Identification of product}

Electrochemical oxidation product of $\mathrm{TCH}$ and $\mathrm{CH}$ involving four electrons have been identified as $\mathrm{NH}_{2} \cdot \mathrm{NH}_{2}, \mathrm{H}_{2} \mathrm{~S}$ for TCH and $\mathrm{NH}_{2} \cdot \mathrm{NH}_{2}, \mathrm{CO}_{2}$ for $\mathrm{CH}$ respectively by the following method. 
Table 2. Cyclic voltammetry data of $2 \mathrm{mM} \mathrm{TCH}$ and $\mathrm{CH}$ at different composition of solvent in Britton-Robinson buffer (electrode system : GCE/Pt/SCE. media $=$ DMSO : Water $\mathrm{pH}=4.63$ )

\begin{tabular}{lccccccc}
\hline \multirow{2}{*}{$\begin{array}{l}\text { DMSO } \\
\text { solvent }(\%)\end{array}$} & \multicolumn{3}{c}{ TCH } & & \multicolumn{3}{c}{$\mathrm{CH}$} \\
\cline { 2 - 3 } \cline { 6 - 7 } & $E_{p a}(\mathrm{mV})$ & $-i_{p a}(\mu \mathrm{A})$ & $D_{0} \times 10^{-5} \mathrm{~cm}^{2} \mathrm{~s}^{-1}$ & & $E_{p a}(\mathrm{mV})$ & $-i_{p a}(\mu \mathrm{A})$ & $D_{0} \times 10^{-5} \mathrm{~cm}^{2} \mathrm{~s}^{-1}$ \\
\hline 20 & 709 & $165 \cdot 2$ & 28.45 & & 858 & $106 \cdot 90$ & $15 \cdot 24$ \\
40 & 806 & $155 \cdot 1$ & $28 \cdot 32$ & & 860 & $96 \cdot 01$ & $12 \cdot 02$ \\
50 & 822 & $117 \cdot 0$ & $16 \cdot 71$ & & 867 & $74 \cdot 90$ & $7 \cdot 48$ \\
60 & 831 & $110 \cdot 2$ & $15 \cdot 03$ & & 874 & $69 \cdot 20$ & $6 \cdot 29$ \\
70 & 907 & $97 \cdot 2$ & 13.58 & & 912 & $60 \cdot 90$ & $5 \cdot 28$ \\
\hline
\end{tabular}

Five $\mathrm{ml}$ of $2 \times 10^{-3} \mathrm{M}$ TCH solution was taken in the cell. $8 \mathrm{ml}$ of DMSO and $10 \mathrm{ml}$ of BrittonRobinson buffer were added. With glassy carbon as a working electrode the solution was subjected to repeated oxidation with a scan rate of $50 \mathrm{mVs}^{-1}$ at a potential range of $0-1500 \mathrm{mV}$. Later the solution was heated and the vapours were held to the lead acetate paper which turned black, thus confirming $\mathrm{COS}$ as the reaction product wherein, carbonyl sulphide combines with water forming $\mathrm{CO}_{2}$ and $\mathrm{H}_{2} \mathrm{~S}$. The product analysis agrees with the findings of potentiometric analysis of TCH and $\mathrm{CH}^{10-12}$

The overall oxidation process can be represented as follows.

$$
\begin{gathered}
\stackrel{\stackrel{\mathrm{S}}{\|}}{\mathrm{H}_{2} \mathrm{~N}-\mathrm{NH}-\mathrm{C}-\mathrm{NH}-\mathrm{NH}_{2}+2 \mathrm{H}_{2} \mathrm{O} \longrightarrow} \\
\mathrm{H}_{2} \mathrm{~N}-\mathrm{NH}_{2}+\mathrm{N}_{2}+\mathrm{H}_{2} \mathrm{~S}+\mathrm{CO}_{2}+4 \mathrm{H}++4 e^{-}
\end{gathered}
$$

$$
\begin{gathered}
\stackrel{\mathrm{O}}{\mathrm{H}_{2} \mathrm{~N}-\mathrm{NH}-\mathrm{C}-\mathrm{NH}-\mathrm{NH}_{2}+\mathrm{H}_{2} \mathrm{O} \longrightarrow} \\
\mathrm{H}_{2} \mathrm{~N}-\mathrm{NH}_{2}+\mathrm{N}_{2}+\mathrm{CO}_{2}+4 \mathrm{H}^{+}+-4 e^{-}
\end{gathered}
$$

On the basis of the above results the following mechanism involving four electrons is proposed for the electrochemical oxidation of $\mathrm{TCH}$ and $\mathrm{CH}$<smiles>[CH+][PH2+]NC(=S)NN</smiles><smiles></smiles>

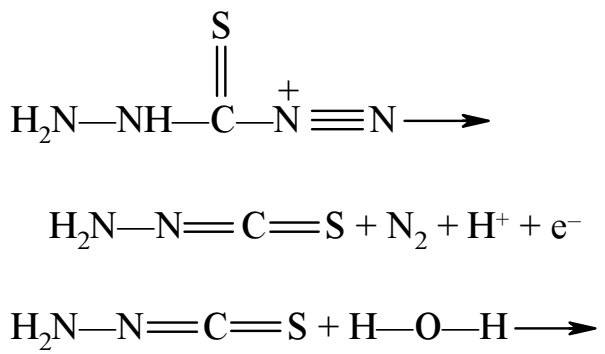<smiles>NNC(O)=S</smiles><smiles>NNC(=S)OCCNNC(=O)O</smiles>

For Carbohydrazide

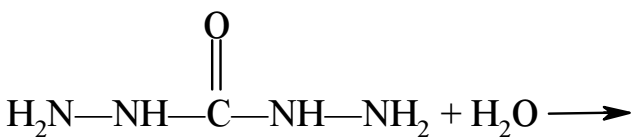

$$
\begin{aligned}
& \mathrm{H}_{2} \mathrm{~N}-\mathrm{NH}_{2}+\mathrm{N}_{2}+\mathrm{CO}_{2}+4 \mathrm{H}^{+}+4 \mathrm{e}^{-}
\end{aligned}
$$

Above $\mathrm{pH} 6.5$ the cyclic voltammogram showed two peaks I, II at $733 \mathrm{mV}, 1050 \mathrm{mV}$ for TCH and $806 \mathrm{mV}$, $1183 \mathrm{mV}$ for $\mathrm{CH}$ respectively, indicating that oxidation takes place in two steps involving three and one electrons. A typical cyclic voltammogram of the 
thiocarbohydrazide and carbohydrazide is shown in figure 2 .

The intermediate product could be<smiles></smiles>

for $\mathrm{TCH}$ and $\mathrm{CH}$ respectively. The mechanism for the two step oxidation process involving three and one electrons can be represented by the following equations.

I step<smiles>NNC(=S)NN</smiles><smiles></smiles><smiles>NNC(=O)CNNC(=O)NN</smiles>

II Step<smiles>[CH2+][PH2+]N=C=C([N+]#[N+]C)NN</smiles>

$\mathrm{H}_{2} \mathrm{~N}-\mathrm{N}=\mathrm{C}=\mathrm{S}+\mathrm{H}_{2} \mathrm{O} \longrightarrow \mathrm{H}_{2} \mathrm{~N}-\mathrm{NH}_{2}+\mathrm{COS}$

Similarly for carbohydrazide

$$
\begin{aligned}
& \stackrel{\mathrm{H}}{\mathrm{H}} \stackrel{\mathrm{N}-\mathrm{N}}{\|}-\mathrm{O}-\stackrel{+}{\mathrm{N}} \equiv \mathrm{N} \longrightarrow \\
& \mathrm{H}_{2} \mathrm{~N}-\mathrm{N}=\mathrm{C}=\mathrm{O}+\mathrm{N}_{2}+\mathrm{H}^{+}+\mathrm{e}^{-} \\
& \mathrm{H}_{2} \mathrm{~N}-\mathrm{N}=\mathrm{C}=\mathrm{O}+\mathrm{H}_{2} \mathrm{O} \longrightarrow \\
& \mathrm{H}_{2} \mathrm{~N}-\mathrm{NH}_{2}+\mathrm{CO}_{2}
\end{aligned}
$$

3.7a. Oxidation of benzaldehyde thiocarbohydra-
zone (BTCH): Eectrochemical oxidation of BTCH
was studied in DMSO-water media using Britton-
Robinson buffer as supporting electrolyte in the po-
tential range -2300 to $1500 \mathrm{mV}$. Single oxidation
peak appeared at potential $-779 \mathrm{mV}$ due to the oxi-
dation of BTCH to benzaldehyde hydrazone. On
subsequent scan $>\mathrm{CH}=\mathrm{N}$ moiety of benzaldehyde
hydrazone further undergoes reduction at potential

3.7a. Oxidation of benzaldehyde thiocarbohydra-
zone (BTCH): Eectrochemical oxidation of BTCH
was studied in DMSO-water media using Britton-
Robinson buffer as supporting electrolyte in the po-
tential range -2300 to $1500 \mathrm{mV}$. Single oxidation
peak appeared at potential $-779 \mathrm{mV}$ due to the oxi-
dation of BTCH to benzaldehyde hydrazone. On
subsequent scan $>\mathrm{CH}=\mathrm{N}$ moiety of benzaldehyde
hydrazone further undergoes reduction at potential

3.7a. Oxidation of benzaldehyde thiocarbohydra-
zone (BTCH): Eectrochemical oxidation of BTCH
was studied in DMSO-water media using Britton-
Robinson buffer as supporting electrolyte in the po-
tential range -2300 to $1500 \mathrm{mV}$. Single oxidation
peak appeared at potential $-779 \mathrm{mV}$ due to the oxi-
dation of BTCH to benzaldehyde hydrazone. On
subsequent scan $>\mathrm{CH}=\mathrm{N}$ moiety of benzaldehyde
hydrazone further undergoes reduction at potential

3.7a. Oxidation of benzaldehyde thiocarbohydra-
zone (BTCH): Eectrochemical oxidation of BTCH
was studied in DMSO-water media using Britton-
Robinson buffer as supporting electrolyte in the po-
tential range -2300 to $1500 \mathrm{mV}$. Single oxidation
peak appeared at potential $-779 \mathrm{mV}$ due to the oxi-
dation of BTCH to benzaldehyde hydrazone. On
subsequent scan $>\mathrm{CH}=\mathrm{N}$ moiety of benzaldehyde
hydrazone further undergoes reduction at potential

3.7a. Oxidation of benzaldehyde thiocarbohydra-
zone (BTCH): Eectrochemical oxidation of BTCH
was studied in DMSO-water media using Britton-
Robinson buffer as supporting electrolyte in the po-
tential range -2300 to $1500 \mathrm{mV}$. Single oxidation
peak appeared at potential $-779 \mathrm{mV}$ due to the oxi-
dation of BTCH to benzaldehyde hydrazone. On
subsequent scan $>\mathrm{CH}=\mathrm{N}$ moiety of benzaldehyde
hydrazone further undergoes reduction at potential

3.7a. Oxidation of benzaldehyde thiocarbohydra-
zone (BTCH): Eectrochemical oxidation of BTCH
was studied in DMSO-water media using Britton-
Robinson buffer as supporting electrolyte in the po-
tential range -2300 to $1500 \mathrm{mV}$. Single oxidation
peak appeared at potential $-779 \mathrm{mV}$ due to the oxi-
dation of BTCH to benzaldehyde hydrazone. On
subsequent scan $>\mathrm{CH}=\mathrm{N}$ moiety of benzaldehyde
hydrazone further undergoes reduction at potential

3.7a. Oxidation of benzaldehyde thiocarbohydra-
zone (BTCH): Eectrochemical oxidation of BTCH
was studied in DMSO-water media using Britton-
Robinson buffer as supporting electrolyte in the po-
tential range -2300 to $1500 \mathrm{mV}$. Single oxidation
peak appeared at potential $-779 \mathrm{mV}$ due to the oxi-
dation of BTCH to benzaldehyde hydrazone. On
subsequent scan $>\mathrm{CH}=\mathrm{N}$ moiety of benzaldehyde
hydrazone further undergoes reduction at potential

3.7a. Oxidation of benzaldehyde thiocarbohydra-
zone (BTCH): Eectrochemical oxidation of BTCH
was studied in DMSO-water media using Britton-
Robinson buffer as supporting electrolyte in the po-
tential range -2300 to $1500 \mathrm{mV}$. Single oxidation
peak appeared at potential $-779 \mathrm{mV}$ due to the oxi-
dation of BTCH to benzaldehyde hydrazone. On
subsequent scan $>\mathrm{CH}=\mathrm{N}$ moiety of benzaldehyde
hydrazone further undergoes reduction at potential

3.7a. Oxidation of benzaldehyde thiocarbohydra-
zone (BTCH): Eectrochemical oxidation of BTCH
was studied in DMSO-water media using Britton-
Robinson buffer as supporting electrolyte in the po-
tential range -2300 to $1500 \mathrm{mV}$. Single oxidation
peak appeared at potential $-779 \mathrm{mV}$ due to the oxi-
dation of BTCH to benzaldehyde hydrazone. On
subsequent scan $>\mathrm{CH}=\mathrm{N}$ moiety of benzaldehyde
hydrazone further undergoes reduction at potential $-1192 \mathrm{mV}$ (figure 4).

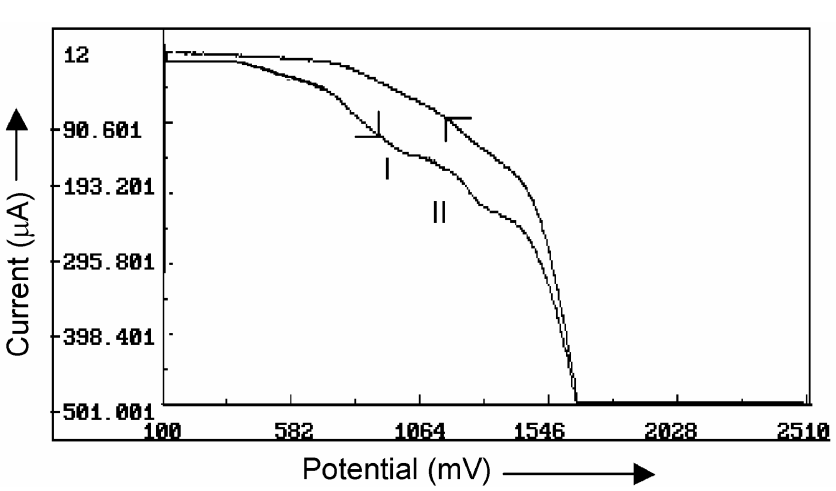

Figure 3. Typical cyclic voltammogram of $2 \mathrm{mM}$ of TCH in DMSO and $0.1 \mathrm{M}$ TBAHFP, scan rate $=50 \mathrm{mVs}^{-1}$ at GCE.
In order to prove the $\mathrm{H}_{2} \mathrm{~N}-\mathrm{NH}_{2}$ is the end product, trial experiment have been conducted by taking hydra- zine and found that it did not undergo oxidation at

\subsection{In non-aqueous media}

TCH in dimethyl sulphoxide in $0 \cdot 1 \mathrm{M}$ tetra butyl ammonium hexa flurophosphate also showed two peaks (I) and (II) at $1000 \mathrm{mV}$ and $1287 \mathrm{mV}$ suggesting that the oxidation process take place in two steps involving three and one electrons respectively. A typical cyclic voltammogram of $\mathrm{TCH}$ is shown in figure 3.

\subsection{Effect of derivatization}

$\mathrm{TCH}$ and $\mathrm{CH}$ form corresponding monocarbohydra$p$-methoxy benzaldehyde respectively. The cv study showed both oxidation and reduction peaks. The reto the reduction of - CHe carbazones could be due peak was due to the oxidation of the free ends of thiocarbohydrazones.

$$
-1192 \mathrm{mV} \text { (figure 4). }
$$


<smiles>CO[PH2+]NC(=S)NN=Nc1ccccc1</smiles>

$\mathrm{C}_{6} \mathrm{H}_{5}-\mathrm{CH}=\mathrm{N}-\mathrm{NH}_{2}+\mathrm{NH}_{2}+\mathrm{N}_{2}+$ $\mathrm{CO}_{2}+\mathrm{H}_{2} \mathrm{~S}+4 \mathrm{H}^{+}+4 \mathrm{e}^{-}$

$$
\begin{gathered}
\mathrm{C}_{6} \mathrm{H}_{5}-\mathrm{CH}=\mathrm{N}-\mathrm{NH}_{2}+4 \mathrm{H}^{+}+4 \mathrm{e}^{-} \longrightarrow \\
\mathrm{C}_{6} \mathrm{H}_{5} \mathrm{CH}_{3}+\mathrm{NH}_{2}-\mathrm{NH}_{2}
\end{gathered}
$$

Separate trial experiments with benzaldehyde hydrazone could prove the point as described below.

Benzaldehyde hydrazone was prepared by refluxing benzaldehyde and hydrazine hydrate for $1 \mathrm{~h}$ in alcohol media. The pale yellow crystals separated out were recrystalised from alcohol.

Electrochemical reduction of Benzaldehyde hydrazone was carried in DMSO-water media using Britton-Robinson buffer in the potential range 0 to $1500 \mathrm{mV}$. Single reduction peak appearing at the potential $-1254 \mathrm{mV}$ (figure 5) agreed with the reduction

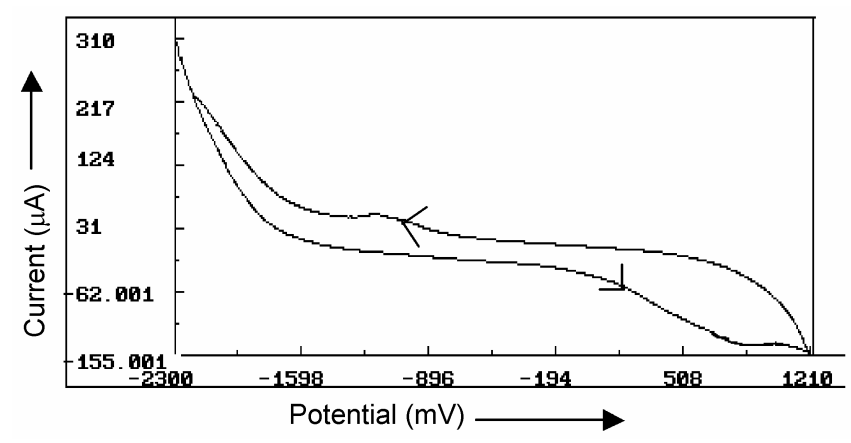

Figure 4. Typical cyclic voltammogram of $2 \mathrm{mM} \mathrm{BTCH}$ in DMSO : water medium, scan rate $=50 \mathrm{mVs}^{-1}$ at GCE .

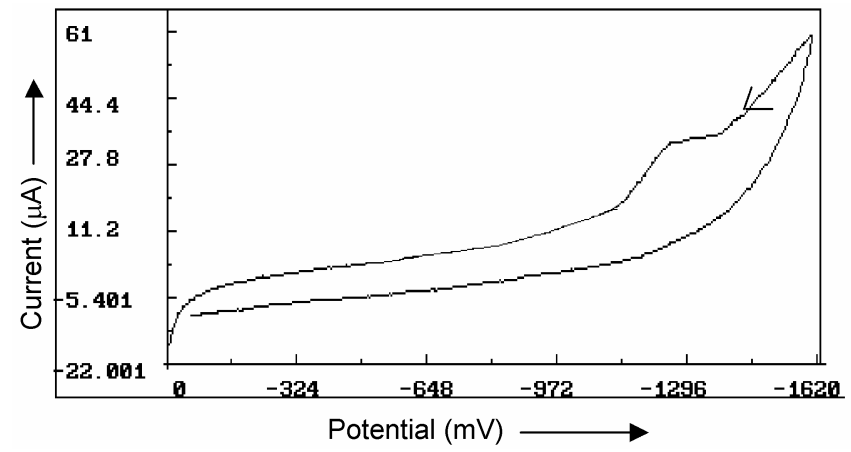

Figure 5. Cyclic voltammogram of $2 \mathrm{mM}$ benzaldehyde hydrazone in DMSO : water medium, scan rate $=50 \mathrm{mVs}^{-1}$ at GCE. of the oxidized product of benzaldehyde thiocarbohydrazone (equation xvi). No new peaks appearing from the multiple scans can be taken as a convincing justification for the formation of $\mathrm{C}_{6} \mathrm{H}_{5} \mathrm{CH}_{3}$ and $\mathrm{NH}_{2}-$ $\mathrm{NH}_{2}$ as reaction products.

\section{7b. Reduction of benzaldehyde thiocarbohydra-} zone: Electrochemical reduction of $\mathrm{BTCH}$ was studied in DMSO-water media using Britton-Robinson buffer as supporting electrolyte in the potential range 1500 to $2000 \mathrm{mV}$. Single peak appeared at $-1887 \mathrm{mV}$ corresponding to the reduction of $\mathrm{HC}=\mathrm{N}$ moiety with a subsequent oxidation peak at the reverse scan confirming quasireversible nature.

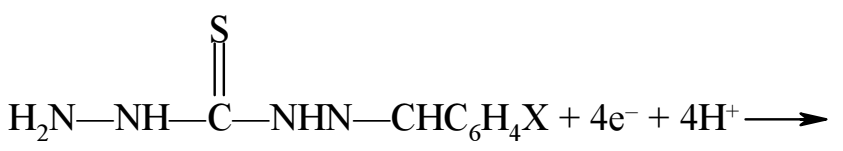

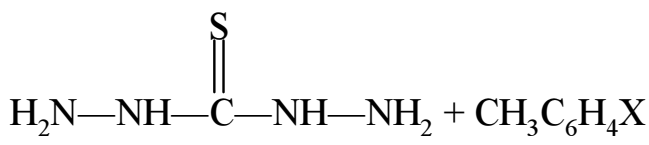

$$
\begin{gathered}
\overbrace{2}^{\mathrm{S}}-\mathrm{NH}-\mathrm{C}-\mathrm{NH}-\mathrm{NH}_{2}+2 \mathrm{H}_{2} \mathrm{O} \longrightarrow \\
\mathrm{H}_{2} \mathrm{~N}-\mathrm{NH}_{2}+\mathrm{N}_{2}+\mathrm{H}_{2} \mathrm{~S}+\mathrm{CO}_{2}+4 \mathrm{H}^{+}+4 \mathrm{e}^{-}
\end{gathered}
$$

where, $\mathrm{X}=-\mathrm{Cl},-\mathrm{OCH}_{3}$.

The typical cyclic voltammogram of the benzaldehyde thiocarbohydrazone is shown in the figure 6 .

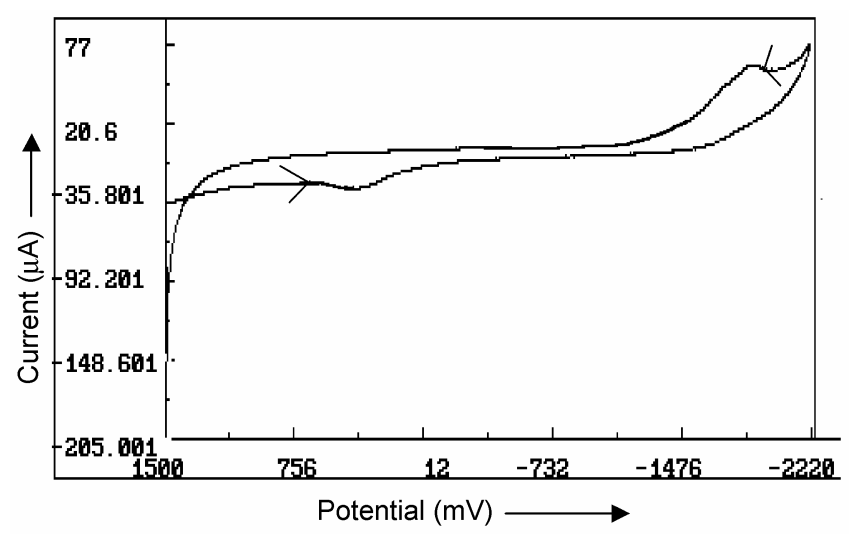

Figure 6. Cyclic voltammogram of $2 \mathrm{mM}$ benzaldehyde thiocarbohydrazone in DMSO : water medium, scan rate $=$ $50 \mathrm{mVs}^{-1}$ at GCE. 
3.7c. Reduction of diacetelydene thiocarbohydrazone: Diacetelydene thiocarbohydrazone was prepared and subjected to cv studies. Single reduction peak appeared at $-1857 \mathrm{mV}$ due to the reduction of two $-\mathrm{HC}=\mathrm{N}-$ moieties, which undergoes oxidation in the subsequent scan indicating the quasireversible process (figure 7). However the oxidation scan in the range 0 to $1500 \mathrm{mV}$, it did not yield any oxidation peak at all. This shows that the molecule is protected against the oxidation due to the formation of hydrazones at both the ends<smiles>C/C=N/NC(=S)N/N=C/C</smiles>

$$
\frac{4 \mathrm{H}^{+}+4 \mathrm{e}^{-}}{\underset{-4 \mathrm{H}^{+},-4 \mathrm{e}^{-}}{\rightleftharpoons}}
$$<smiles>CCNNC(=S)NNCC</smiles>

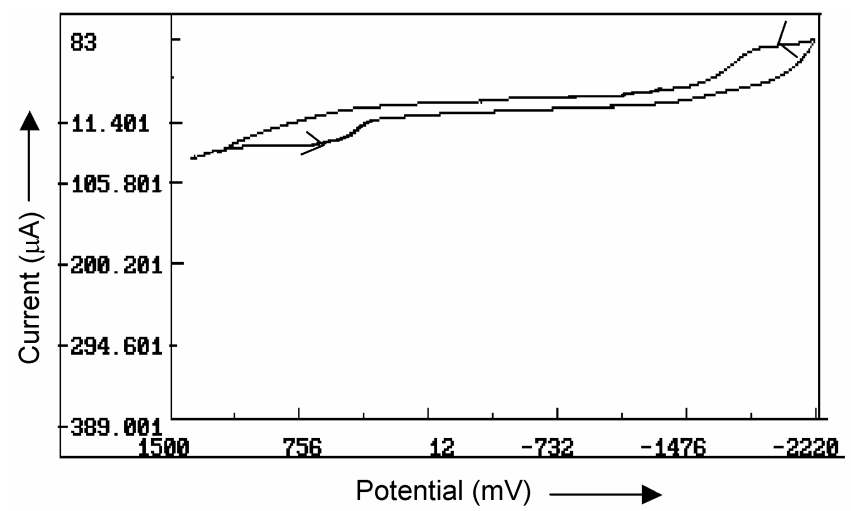

Figure 7. Cyclic voltammogram of $2 \mathrm{mM}$ diacetelydene thiocarbohydrazone in DMSO: water medium, scan rate $=50 \mathrm{mVs}^{-1}$ at $\mathrm{GCE}$.

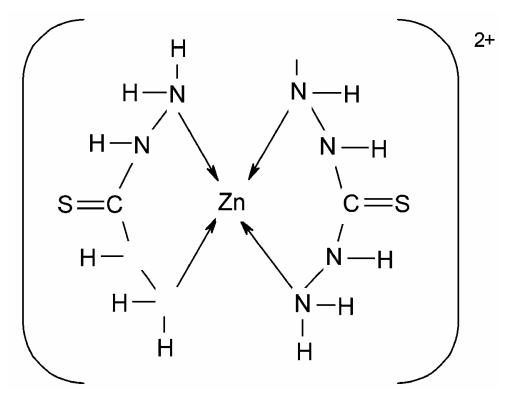

Figure 8. Structure of a typical metal complex of thiocarbohydrazide, where $\mathrm{M}=\mathrm{Zn}$, the complex is bis(thiocarbohydrazide) zinc(II) ion.

\subsection{Effect of complexation}

Effect of complexation was studied by preparing the complex bis(thiocarbohydrazide) zinc(II) chloride. Structure of bis(thiocarbohydrazide) zinc(II) ion is shown in figure 8 .

The Zn (II) complex of TCH in Britton Robinson buffer of $\mathrm{pH} 6.3$ at GCE was subjected to $\mathrm{CV}$ studies at a potential range of 0 to $1500 \mathrm{mV}$. No oxidation peak was observed but in the potential range of 0 to $-1110 \mathrm{mV}$ although it showed a reduction peak at $-869 \mathrm{mV}$. This indicated that the metal ion complex undergoes reduction and the ligand will not take part in the redox process.

On comparing the reduction potential of pure $\mathrm{ZnCl}_{2}$ with that of $\mathrm{Zn}$ complex of $\mathrm{TCH}$, it was observed that the pure $\mathrm{ZnCl}_{2}$ got reduced at lower potential $-743 \mathrm{mV}$. whereas, $\mathrm{Zn}$ complex was reduced only at a higher potential of $-869 \mathrm{mV}$ (figure 9).

This suggest that metal in the free state gets reduced at lower potential than in the metal bound formation.

\subsection{Differential pulse voltammetry at GCE}

Differential pulse voltammetry makes a still greater improvement in sensitivity. The current is measured twice- once before applying the pulse and again during the last $17 \mathrm{~ms}$ of the pulse. The first current is instrumentally subtracted from the second current. The differential pulse voltammetry is thus a plot of current difference versus applied potential. In order

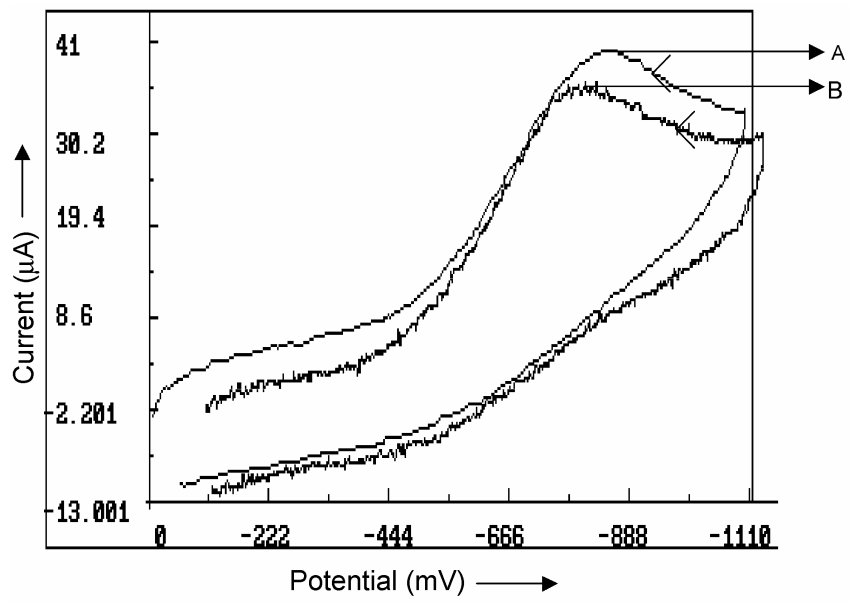

Figure 9. Cyclic voltammogram of $2 \mathrm{mM} \mathrm{Zn}$ (II) complex of $\mathrm{TCH}$ (a) and pure $\mathrm{ZnCl}_{2}$ (b) in DMSO : water medium, scan rate $=50 \mathrm{mVs}^{-1}$ at GCE. 


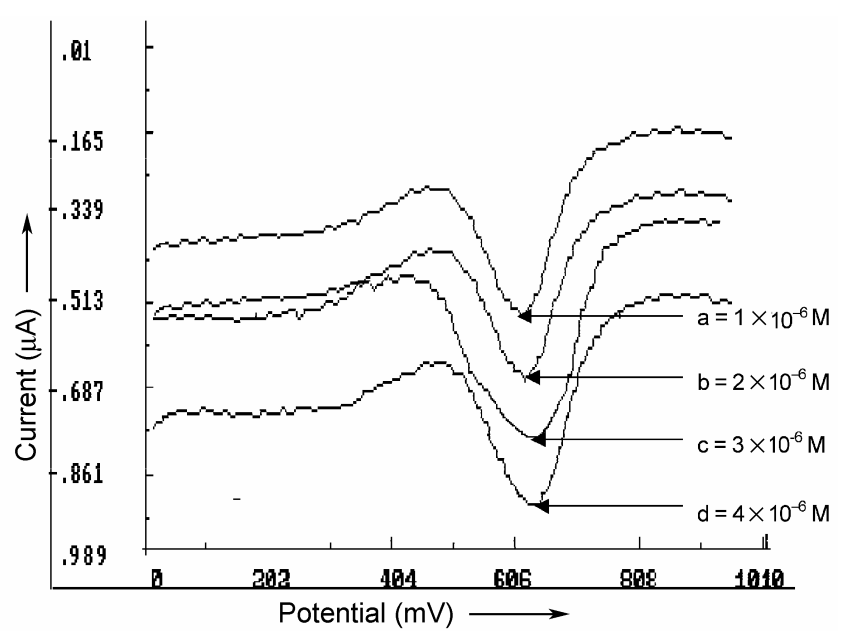

Figure 10. Differential pulse voltammograms for standard addition of $1 \times 10^{-6}$ to $4 \times 10^{-6} \mathrm{M}$ of thiocarbahydrazide at GCE. Pulse amplitude $=50 \mathrm{mV}$, supporting electrolyte: Britton-Robinson buffer.

to know the concentration of TCH we compared the anodic peak obtained by differential pulse voltammetry. The best ratio of peak to background currents was obtained with differential pulse voltammetry for pulse amplitude of $50 \mathrm{mV}$ and this was used in subsequent studies. The figure 10 shows the voltammogram of TCH on addition of 1 to $4 \mu \mathrm{M}$ of TCH. The DPV curves are illustrated with $a, b, c$ and $d$ indicating their respective concentrations.

\section{Conclusion}

The anodic peak potentials for TCH and its derivatives are shifted to more positive values with increase in concentration of electroactive species. The electron withdrawing or electron donating group in the hydrazone derivative retard or accelerate the oxidation process.

The anodic peak current was found to increase linearly with square root of sweep rate and also with concentration of electroactive species, suggesting that the overall electrode process is diffusion controlled and irreversible.

At higher surfactant concentration (within critical micelle concentration) no oxidation peak was observed.
Bis(thiocarbohydrazide) zinc(II) complex shows reduction and not oxidation. Differential pulse voltammetry for the determination of microgram quantities of TCH yielded reproducible results.

\section{References}

1. Loc P T B 1966 Compt. Rend. Soc. Biol. 16036

2. Cline R E and Pearce G W 1966 J. Insect. Phisiol. 12 153

3. Gausman H W, Rhykerd, C L Hinderliter H R, Scott E S and AudriethL F 1953 Bottan. J. Gaz. 114 292; 1953 Chem. Abstr. 478955

4. Clayton D W and Marraccini L M 1966 Papperstid. S $69311 ; 1966$ Chem. Abstr. 659160

5. Gordon J A and Jencks W P 1963 Biochemistry 247

6. Levin L Gordon J A and Jencks W P1963 Biochemistry 3168

7. Kartvelishvili T E, Soobscheniya 1960 Akad. Nauk. Gruzin. 24 231, through 1961 Chem. Abstr. 551912

8. Levine H H 1959 US patent 3,014,009; 1962 Chem. Abstr. 568932

9. Thoma W 1965 Belgian patent 660,945; 1966 Chem. Abstr. 642025

10. Thimmegowda B and Sherigara B S 1989 Proc. Indian Acad. Sci. (Chem. Sci.) 101155

11. Ivan Pinto $1992 \mathrm{PhD}$ thesis studies on redox reactions of manganese(III) in solution (submitted to Mangalore University)

12. Raviprakash S D Sherigara B S and Abudal Khader A M 1993 Indian J. Chem. A32 58

13. Sherigara B S, Kumaraswamy B E, Subrahmanyam E V S and Ishwar Bhat K 2001 Int. J. Chem. Kinet. 3319

14. Mamatha G P, Sherigara B S, Mahadevan K M, Kumaraswamy B E 2005 Bull. Electrochem. 219

15. Siddalingaiah A H M, Naik S G, Sherigara B S and Kumaraswamy B E 2002 J. Mol. Struct. (Theo-chem.) 58269

16. Ronald Mascarenhas J, Irishi Namboothiri N, Sherigara B S, Mahadevan K M and Kumaraswamy B E 2006 crotica chimica Acta. (accepted)

17. Sherigara B S, Shivaraj Y, Ronald Mascarenhas, Satpati A K 2006 Electrochim. Acta (accepted)

18. Burns G R 1968 Inorg. Chem. 7277

19. Kurzer I and Wilkinson M 1970 Chem. Rev.70 111 and references there in

20. Nicholson R S and Shain I 1964 Anal. Chem. 36722

21. Adam R N and Marcel Dekker 1996 Electrochemistry at Solid Electrodes

22. Bard A J and Fauklner R L 1980 Electrochemical methods, fundamentals and application (Wiely) 2189, 222.

23. Cisak A 1962 Rolz. Chim. 361895 